\title{
OCCLUSAL CHARACTERISTICS IN A GROUP OF CHILDREN WITH CEREBRAL PALSY IN ALEXANDRIA EGYPT
}

\author{
Sara H. El Rouby ${ }^{1} B D S$, Karin M.L. Dowidar ${ }^{2} P h D$, Amel M. Ahmed ${ }^{3} P h D$, Tarek E.I. Omar ${ }^{4}$ \\ $P h D$
}

\begin{abstract}
INTRODUCTION: Cerebral palsy is the term given for a range of non-progressive syndromes of posture and motor impairment that results from an insult to the developing central nervous system.

OBJECTIVES: Assess the occlusal characteristics in children with cerebral palsy and relate them to the degree of their neuromuscular deficit. MATERIALS AND METHODS: The study included 87 children with cerebral palsy and 84 healthy children from Alexandria, Egypt. Data were collected using a questionnaire and clinical examination. Questionnaire assessed socio-demographics and medical history. Clinical examination assessed facial profile, posterior occlusion, cuspid relationships, posterior crossbite and anterior incisor relationships.

RESULTS: Class II cuspid relationship was statistically higher in cerebral palsy children than healthy control ( $\mathrm{P}=0.02$ for both sides). 29.9\% of cerebral palsy children and $15.5 \%$ of healthy children had convex facial profile with significant difference ( $\mathrm{P}=0.04)$. Cerebral palsy children were more likely to have open bite than healthy children (31.1\% and $14.8 \%$ respectively) with a statically significant difference between both groups $(\mathrm{P}=0.02)$. The mean overjet $(\mathrm{mm})$ was higher in cerebral palsy children than healthy children ( 2.87 and $2.23 \mathrm{~mm}$ respectively) with a statically significant difference $(\mathrm{P}=0.03$ ) and the mean overbite $(\%)$ was also higher in cerebral palsy children than healthy children (40.65\% and $25.47 \%$ respectively) with a significant difference $(\mathrm{P}=0.001)$.

CONCLUSIONS: Cerebral palsy children had a convex facial profile with class II cuspid relationship in comparison to the healthy children. Anteriorly, cerebral palsy children exhibited an increased open bite with a higher significant mean number of overbite and overjet than healthy children. The posterior occlusal relationships in children with cerebral palsy were similar to that in healthy children. The severity of the neuromuscular deficit is a risk factor for the development of malocclusion in cerebral palsy children.
\end{abstract}

KEYWORDS: Cerebral Palsy, Occlusion, neuromuscular deficit, Gross Motor Function Classification System

1-Instructor at Pediatric Dentistry and Dental Public Health Department, Faculty of Dentistry, Alexandria University, Alexandria, Egypt.

2-Professor at Pediatric Dentistry and Dental Public Health Department Faculty of Dentistry, Alexandria University, Alexandria, Egypt.

3-Assistant professor at Pediatric Dentistry and Dental Public Health Department Faculty of Dentistry, Alexandria University, Alexandria, Egypt.

4- Professor at Department of Pediatrics, Faculty of Medicine, Alexandria University, Alexandria, Egypt

Corresponding author:

Email: elroby.sara@gmail.com

\section{INTRODUCTION}

Cerebral palsy (CP) is the term given for a range of nonprogressive syndromes of posture and motor impairment that results from an insult to the developing central nervous system (1). It is the most common cause of severe physical disability in childhood (2). The prevalence of CP is 2.4 per 1000 children in both developed and developing countries (3). Cerebral Palsy patients have some similar characteristics, including: the inability to perform smooth motions due to excessive muscle tonus (4), oral motor disorders and difficulties in eating, swallowing, and chewing $(5,6)$.

Children with CP display comparable oral features as healthy persons. However, they present a higher susceptibility to several oro-dental diseases (dental caries, periodontal disease, dental trauma, malocclusion, bruxism, temporo-mandibular joint disorders, enamel hypoplasia, abnormal oral habits, drooling etc.) due to abnormal neuromuscular coordination of the tongue, lips, and cheeks and to the low level and the reduced quality of the oral care $(5,7)$. The muscles of the face and oral cavity play a role in facial growth and occlusal development (8). As the tone and function of the orofacial muscles with CP can be abnormal, the facial growth and occlusion of these children may be outside normal limits (9).
Several studies in the literature have reported conflicting results regarding the prevalence of malocclusion in children with CP. Some studies have found an increased prevalence of malocclusion (10-12). Franklin et al., 1996 (10) in United Kingdom reported that Class II molar relationship and increased overbite were more prevalent in CP children. In addition, Miamoto et al., 2010 (11) in Brazil found that patients with cerebral palsy had a greater prevalence of malocclusion compared with healthy subjects. Moreover, in a study conducted on CP children in India, Chandna et al., 2011 (12) observed that majority of the children (60\%) had Class II malocclusion and 70.58\% spastic cerebral palsy children have Class II malocclusion. On the contrary others have found the prevalence of malocclusion to be within normal limits $(13,14)$. Rosenbaum et al., 1966 (13) concluded that the total prevalence of malocclusion among cerebral palsy children is not found in greater frequency than normal children.

There is inadequate information about the prevalence of malocclusion among patients with cerebral palsy in Egypt. Therefore, this study aimed at filling this gap by assessing the occlusal characteristics in children with cerebral palsy and relates them to the degree of their neuromuscular deficit. This allows dentists to respond to the needs of this vulnerable group of children with limited healthcare resources. The null hypothesis of the present study is that 
there is no difference in the prevalence of malocclusion between CP and healthy children and the degree of neuromuscular deficit has no effect on the development of malocclusion in CP patients.

\section{MATERIALS AND METHODS}

A cross-sectional analytical study was conducted in Alexandria, Egypt, in the period from 2015 to 2017.

\section{Ethical Considerations}

Ethical approval for the study was obtained from the Dental Research Ethics Committee, Faculty of Dentistry, Alexandria University. Acceptance from Alexandria University Children's Hospital (AUCH) and the different institutions were obtained before the beginning of the study. The children's parents were asked to sign an informed consent after being informed about the purpose of the study and about the confidentiality of the collected information. Dental health education was carried out to all the patients. Children were referred to the pediatric dental clinic to receive dental treatment when needed.

\section{Study sample}

One hundred seventy-one children with an age range from 3 to 13 years were selected to participate in the study. Children with CP were recruited from Alexandria University Children's Hospital (AUCH) and its outpatientclinics (Neurology and Physical Medicine) and from different institutions (Fairhaven school, New Vision institution). Healthy children were selected from siblings of children attending the Pediatric Dental Clinic, Pediatric Dentistry and Dental Public Health department, Faculty of Dentistry, Alexandria University.

The sample size was estimated based on these assumptions: Type 1 error $=5 \%$ and Type 2 error $=20 \%$. Estimated difference between mean DMF in the two groups $=1.16$, with standard deviations in the 2 groups $=2.62$ and 2.75 . Using MedCalc for sample size calculation, the minimum required sample size was estimated to be 84 (15).

\section{Data were collected using the following methods:}

\section{Questionnaire (16).}

Intraoral examination (16).

\section{Questionnaire}

The researcher collected the following information from the child's parent or guardian and from his medical records. The questionnaire was developed in Arabic language and was filled by the examiner for both groups of children before the oral examination (16). Socio-demographic data were collected including name, age and gender of the child with birth order among siblings as well as phone number and name of the school. Parental occupation and education were also recorded. Medical history was gathered for both cerebral palsy and healthy children.

For cerebral palsy children their medical information was collected from their records that included prenatal, perinatal, postnatal etiological factors and the clinical type of movement disorder whether spastic, dyskinetic, ataxic, or a mixture of these disorders. The topographic patterns of involvement of CP children were also documented varying from total body involvement (quadriplegic) to double hemiplegia or partial body involvement (diplegic or hemiplegic) (17). The severity of CP was recorded using the Gross Motor Function Classification System (GMFCS) levels I-V. Level I being the mildest in the following age groups: up to 2 yrs, 2 - 4 yrs, 4 - 6 years and between 6 to 12 years. For each level, separate descriptions are provided
(18). Regarding the healthy children their parents were asked if they are suffering from any medical condition.

\section{Intraoral examination}

-Cerebral palsy children (Group I): Intraoral examination was performed under good illumination while they were lying on the examination table or on their parent's leg or on their wheelchair according to the available facilities. Although the examination was noninvasive, the examiner used universal precautions for infection control using disposable diagnostic sets including gloves, mirror, explorer and sterilized gauze to clean and dry teeth.

-Healthy children (Group II): Intraoral examination was conducted while the children were seated on the dental chair.

Clinical assessment of occlusion included $(19,20)$ :

i. Facial profile: the line connecting 3 points on the face (bridge of nose, base of upper lip, chin) forming an angle that describes facial profile; classified as concave, convex or straight. Each patient was examined clinically by the observer in their natural head position (NHP) seated comfortably on either the dental chair, wheel chair or the examination table in upright position (16).

ii. Posterior occlusion relationships: For primary dentition, posterior occlusion assessment was based on terminal plan relation which described the relationship of the distal surfaces of the primary mandibular second molar to distal surface of the primary maxillary second molar. Classified either mesial step, distal step or flushed for both sides. For mixed and permanent dentition, it was based on Angle's classification of occlusion recorded as class I, class II, or class III for both sides; according to the occlusion of the mesiobuccal cusp of the upper first permanent molar in the buccal groove of the lower first permanent molar. When first permanent molars were missing or not fully erupted, the registration was considered not applicable.

iii. Cuspid relationships: For both primary and permanent dentition, canine relationship was determined by the relationship of the maxillary canine to the embrasure between mandibular canine and first premolar (or first primary molar) and were recorded as class I, class II, or class III for both sides. When canines were missing or not fully erupted, the registration was considered not applicable.

iv. Posterior crossbite: was registered when there was abnormal buccolingual relationship of the teeth. Posterior crossbite was recorded as being present if the buccal cusps of the lower first permanent molars occluded outside the buccal cusps of the upper first permanent molars. Lingual crossbite was not included in this study.

v. Assessment of anterior relations (over jet, overbite):

Overbite: is the vertical overlap of the incisors and is measured from the incisal edge of one incisor to the other. Overbite was recorded in percentage.

Overjet: is the horizontal overlap of the maxillary and mandibular central incisors and is measured in $\mathrm{mm}$ from the most anterior point on the facial surfaces of the incisors.

vi. Anterior open bite: is the absence of vertical overlap when the teeth are in occlusion. An anterior open bite was recorded as being present if the lower incisors were not overlapped in the vertical plane by the upper incisors, and did not occlude with them.

Statistical analysis:

Statistical analysis was carried out using SPSS version 
16.0 (SPSS Inc. Chicago, IL, USA). Descriptive statistics were displayed as mean \pm standard deviation for quantitative variables and frequencies and percents for qualitative variables. Cerebral palsy and healthy children groups were compared with regards to father and mother education and occupation using chi-square test. Occlusal relations and characteristics were compared among cerebral palsy and healthy children groups and among cerebral palsy children with different degree of neuromuscular deficit using chisquare test or Fisher's exact test. Overbite and overjet were compared using t test. Significance level was set at the $5 \%$

\section{RESULTS}

The present study included 171 children, 87 cerebral palsy children and 84 healthy controls. Their ages ranged between 3and 13 years. The mean age of cerebral palsy children was $5.7( \pm 2.9)$ years whereas the mean age of healthy children was $6.2( \pm 2.3)$ years. The study group consisted of 47 (54\%) males and 40 (46\%) females. The control group consisted of 42 (50\%) male and 42 (50\%) female. As many as 27.6\% of fathers of cerebral palsy children were illiterate whereas $20.7 \%$ of fathers were university graduates. As for healthy control children, $7.1 \%$ of fathers were illiterate whereas $19 \%$ of them were university graduates, with a statistically significant difference between both groups $(\mathrm{P}<0.0001)$.

Regarding mother education, $24.1 \%$ of mothers of cerebral palsy children were illiterate whereas $32.2 \%$ of mothers were university graduates. As for healthy children, 9.5\% of mothers were illiterate whereas $25 \%$ of them were university graduates, with a statistically significant difference between both groups $(\mathrm{P}=0.008)$. Regarding father's and mother's occupation, there was no statistically significant difference between both groups $(\mathrm{P}=0.06$ and 0.73 respectively).

According to their medical records, majority of the cerebral palsy children exhibited spastic CP (83.9\%) and the other types (Dyskinetic -ataxic) were each distributed among approximately (16.1\%) of the sample. Regarding topographic distribution, a large portion of the children exhibited quadriplegia (65.1\%). According to GMFCS, $20.7 \%$ of children were classified as level I/ II, 21.8\% were Level III while $25.3 \%$ were level IV and $32.2 \%$ were Level V. (Figure 1)

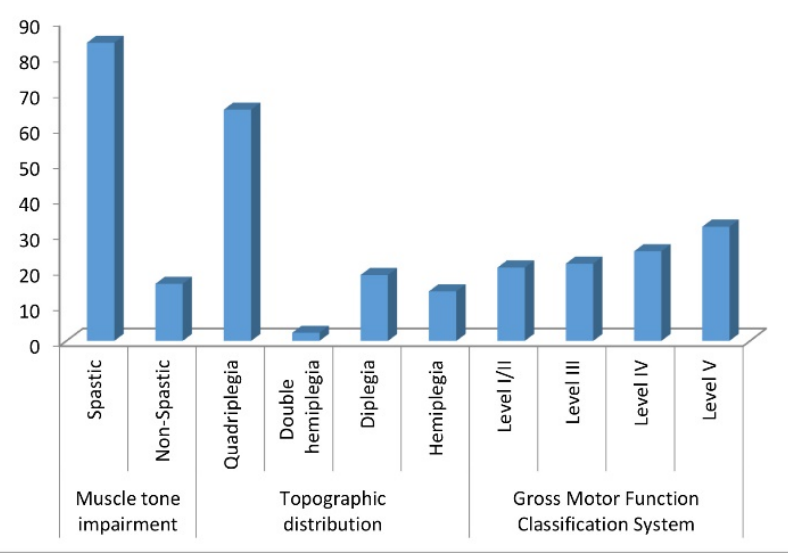

Figure 1: Distribution of cerebral palsy children according to their motor impairment and the severity of the neuromuscular deficit.

For cerebral palsy children, convex facial profile was observed more in spastic CP children (35.6\%) while none of the non-spastic $\mathrm{CP}$ children had convex facial profile with a significant difference $(\mathrm{P}=0.023)$. The overbite in spastic CP children was significantly lower than non-spastic children $(57.27 \%$ and $37.06 \%$ respectively) with a significant difference $(\mathrm{P}=.02)$.

Table 1 shows terminal plane, molar relation and cuspid relation among cerebral palsy and healthy children. There was no statistically significant difference between the two groups regarding the terminal plane relation for both sides ( $\mathrm{P}=0.135$ and 0.082 for right side and left side respectively) and the molar relation for both sides $(\mathrm{P}=0.10$ and 0.15 for right and left sides respectively). There was a statistically significant difference between both groups regarding the cuspid relation for both sides $(\mathrm{P}=0.02$ and 0.01 for right and left sides respectively).

Table 1. Occlusal relations among cerebral palsy and healthy children

\begin{tabular}{|c|c|c|c|c|}
\hline Occlusal relations & & $\begin{array}{l}\text { Cerebral } \\
\text { palsy } \\
\text { children } \\
\text { N (\%) }\end{array}$ & $\begin{array}{c}\text { healthy } \\
\text { children } \\
\text { N (\%) }\end{array}$ & P value \\
\hline \multirow[t]{3}{*}{$\begin{array}{l}\text { Terminal plane } \\
\text { relation right }\end{array}$} & $\begin{array}{l}\text { Mesial } \\
\text { step }\end{array}$ & $46(82.1)$ & 46(92) & \multirow[t]{3}{*}{0.135} \\
\hline & Flush & $10(17.9)$ & $4(8)$ & \\
\hline & $\begin{array}{c}\text { Distal } \\
\text { step }\end{array}$ & $0(0)$ & $0(0)$ & \\
\hline \multirow[t]{3}{*}{$\begin{array}{l}\text { Terminal plane } \\
\text { relation left }\end{array}$} & $\begin{array}{l}\text { Mesial } \\
\text { step }\end{array}$ & $46(82.1)$ & 46(92) & \multirow[t]{3}{*}{0.082} \\
\hline & Flush & $10(17.9)$ & $3(6)$ & \\
\hline & $\begin{array}{l}\text { Distal } \\
\text { step }\end{array}$ & $0(0)$ & $1(2)$ & \\
\hline \multirow[t]{3}{*}{$\begin{array}{l}\text { Molar relation } \\
\text { Right }\end{array}$} & $\begin{array}{c}\text { Class } \\
\text { I }\end{array}$ & $24(77.4)$ & $26(81.2)$ & \multirow[t]{3}{*}{0.10} \\
\hline & $\begin{array}{l}\text { Class } \\
\text { II }\end{array}$ & $7(22.6)$ & $3(9.4)$ & \\
\hline & $\begin{array}{c}\text { Class } \\
\text { III }\end{array}$ & $0(0)$ & $3(9.4)$ & \\
\hline \multirow[t]{3}{*}{$\begin{array}{l}\text { Molar relation } \\
\text { Left }\end{array}$} & $\begin{array}{l}\text { Class } \\
\text { I }\end{array}$ & $24(77.4)$ & $27(84.4)$ & \multirow[t]{3}{*}{0.15} \\
\hline & $\begin{array}{c}\text { Class } \\
\text { II } \\
\end{array}$ & $7(22.6)$ & $3(9.4)$ & \\
\hline & $\begin{array}{c}\text { Class } \\
\text { III }\end{array}$ & $0(0)$ & $2(6.2)$ & \\
\hline \multirow[t]{3}{*}{$\begin{array}{l}\text { Cuspid relation } \\
\text { Right }\end{array}$} & $\begin{array}{c}\text { Class } \\
\text { I }\end{array}$ & $58(71.6)$ & $68(86.1)$ & \multirow[t]{3}{*}{$0.02 *$} \\
\hline & $\begin{array}{l}\text { Class } \\
\text { II }\end{array}$ & $19(23.5)$ & $6(7.6)$ & \\
\hline & $\begin{array}{c}\text { Class } \\
\text { III }\end{array}$ & $4(4.9)$ & $5(6.3)$ & \\
\hline \multirow[t]{3}{*}{$\begin{array}{l}\text { Cuspid relation } \\
\text { Left }\end{array}$} & $\begin{array}{c}\text { Class } \\
\mathrm{I} \\
\end{array}$ & $58(71.6)$ & 72(90) & \multirow[t]{3}{*}{$0.01^{*}$} \\
\hline & $\begin{array}{c}\text { Class } \\
\text { II }\end{array}$ & 19(23.5) & $7(8.8)$ & \\
\hline & $\begin{array}{l}\text { Class } \\
\text { III }\end{array}$ & $4(4.9)$ & $1(1.2)$ & \\
\hline
\end{tabular}

Table 2 shows facial profile, posterior crossbite, open bite, overjet and overbite among cerebral palsy and healthy children. Regarding facial profile $29.9 \%$ of cerebral palsy children and $15.5 \%$ of healthy children have convex facial profile and $69 \%, 79.8 \%$ of cerebral palsy and healthy children have straight facial profile respectively with significant difference $(\mathrm{P}=0.04)$.

It was found that there was no statistically significant difference between the two groups regarding posterior crossbite ( $\mathrm{P}=1$ for both sides). As regards open bite, cerebral palsy children are more likely to have open bite than healthy 
children (31.4\% and 14.8\% respectively) with a statically significant difference between both groups $(\mathrm{P}=0.02)$.

Regarding the mean overjet ( $\mathrm{mm})$, it was higher in cerebral palsy children than healthy children were $(2.87 \mathrm{~mm}$ and $2.23 \mathrm{~mm}$ respectively) with a statically significant difference $(\mathrm{P}=0.03)$ and the mean overbite $(\%)$ was also higher in cerebral palsy children than healthy children (40.65\% and $25.47 \%$ respectively) with a significant difference $(\mathrm{P}=0.001)$.

Table 2: Facial profile, posterior crossbite, open bite, overbite and overjet among cerebral palsy and healthy children

\begin{tabular}{|c|c|c|c|c|}
\hline Occlusion & & $\begin{array}{c}\text { Cerebral } \\
\text { palsy } \\
\text { children } \\
\text { N (\%) }\end{array}$ & $\begin{array}{c}\text { Healthy } \\
\text { children } \\
\text { N (\%) }\end{array}$ & $P$ value \\
\hline \multirow[t]{3}{*}{ Facial profile } & Concave & 1(1.1) & $4(4.8)$ & \multirow[t]{3}{*}{$0.04 *$} \\
\hline & Convex & 26(29.9) & 13(15.5) & \\
\hline & straight & $60(69)$ & $67(79.8)$ & \\
\hline \multirow[t]{2}{*}{ Post crossbite } & No & $83(95.4)$ & $79(94)$ & \multirow[t]{2}{*}{.74} \\
\hline & yes & $4(4.6)$ & $5(6)$ & \\
\hline \multirow[t]{2}{*}{ Open bite } & No & 51(68.9) & $69(85.2)$ & \multirow[t]{2}{*}{$0.02 *$} \\
\hline & Yes & 23(31.1) & $12(14.8)$ & \\
\hline Overjet in mm & $\begin{array}{l}\text { Mean } \\
(\mathrm{SD})\end{array}$ & $\begin{array}{c}2.87 \\
(1.85)\end{array}$ & $\begin{array}{c}2.23 \\
(1.26)\end{array}$ & $0.03^{*}$ \\
\hline $\begin{array}{l}\text { Overbite in } \\
\text { Percentage }\end{array}$ & $\begin{array}{l}\text { Mean } \\
(\mathrm{SD})\end{array}$ & $\begin{array}{c}40.65 \\
(26.48)\end{array}$ & $\begin{array}{c}25.47 \\
(21.23)\end{array}$ & $0.001 *$ \\
\hline
\end{tabular}

*: Statistically significant at $\mathrm{p}<0.05$

Table 3 shows the relation between occlusion characteristics and the degree of neuromuscular deficit in CP Children. Regarding the facial profile, there was a significant difference between it and the four levels of $\mathrm{CP}$ as determined by GMFCS ( $\mathrm{P}=0.001) .46 .4 \%$ of $\mathrm{CP}$ children with Level $\mathrm{V}$ had convex facial profile and (50\%) had straight facial profile while, $(11.1 \%)$ of CP children with level I/II had convex facial profile and (88.9\%) had straight facial profile. No significant differences were found between the four levels of CP as determined by GMFCS and molar relationship on both sides $(\mathrm{P}=0.208$ for right and left sides) as well as cuspid relationship on both sides $(\mathrm{P}=0.084$ and 0.120 for right and left respectively).

Regarding the terminal plane relationship on both sides there was a significant difference between the primary molar relationship and the four levels of $\mathrm{CP}(\mathrm{P}=0.034$ for both sides). (92.9\%) of CP children with level I/II had mesial step and $(7.1 \%)$ had flush terminal plane while, (68.4\%) of CP children with level V had mesial step and (26.3\%) had flush terminal plane as well as (5.3\%) had distal step. There was a statically significant difference between the four levels of $\mathrm{CP}$ and their respective open bite prevalence $(\mathrm{P}=0.003)$ where, $5.9 \%$ of $\mathrm{CP}$ children with level I/II had open bite while, $42.4 \%$ of CP children with level V had open bite.
Table 3: Relation between occlusion characteristics and the degree of neuromuscular deficit in cerebral palsy children

\begin{tabular}{|c|c|c|c|c|c|c|}
\hline Variable & $\begin{array}{c}\text { Variable } \\
\text { categori } \\
\text { es }\end{array}$ & $\begin{array}{c}\text { Level } \\
\text { I/ II } \\
\text { N (\%) }\end{array}$ & $\begin{array}{c}\text { Level } \\
\text { III } \\
\text { N (\%) }\end{array}$ & $\begin{array}{c}\text { Level } \\
\text { IV } \\
\text { N (\%) }\end{array}$ & $\begin{array}{c}\text { Level V } \\
\text { N (\%) }\end{array}$ & $\begin{array}{c}\mathbf{P} \\
\text { value }\end{array}$ \\
\hline \multirow{3}{*}{$\begin{array}{l}\text { Facial } \\
\text { profile }\end{array}$} & Concave & $0(.0 \%)$ & $0(.0 \%)$ & $0(.0 \%)$ & $1(3.6 \%)$ & \multirow{3}{*}{$.001^{*}$} \\
\hline & Convex & $\begin{array}{c}2 \\
(11.1 \%)\end{array}$ & $\begin{array}{c}3 \\
(15.8 \%)\end{array}$ & $\begin{array}{c}8 \\
(36.4 \%)\end{array}$ & $\begin{array}{c}13 \\
(46.4 \%)\end{array}$ & \\
\hline & Straight & \begin{tabular}{|c|}
16 \\
$(88.9 \%)$ \\
\end{tabular} & $\begin{array}{c}16 \\
(84.2 \%) \\
\end{array}$ & $\begin{array}{c}14(63.6 \\
\%) \\
\end{array}$ & $\begin{array}{c}14 \\
(50.0 \%) \\
\end{array}$ & \\
\hline \multirow{2}{*}{$\begin{array}{l}\text { Molar } \\
\text { relationship } \\
\text { right }\end{array}$} & Class I & $\begin{array}{c}3 \\
(75.0 \%) \\
\end{array}$ & $\begin{array}{c}4 \\
(57.1 \%) \\
\end{array}$ & 7 (7.8\%) & $\begin{array}{c}10 \\
(90.9 \%)\end{array}$ & \multirow{2}{*}{.208} \\
\hline & Class II & $\begin{array}{c}1 \\
(25.0 \%) \\
\end{array}$ & $\begin{array}{c}3 \\
(42.9 \%) \\
\end{array}$ & $\begin{array}{c}2 \\
(22.2 \%) \\
\end{array}$ & $1(9.1 \%)$ & \\
\hline \multirow[t]{2}{*}{$\begin{array}{l}\text { Molar } \\
\text { relationship } \\
\text { left } \\
\end{array}$} & Class I & $\begin{array}{c}3 \\
(75.0 \%)\end{array}$ & $\begin{array}{c}4 \\
(57.1 \%)\end{array}$ & $\begin{array}{c}7 \\
(77.8 \%)\end{array}$ & $\begin{array}{c}10 \\
(90.9 \%)\end{array}$ & \multirow[t]{2}{*}{.208} \\
\hline & Class II & $125.0 \%$ & $\begin{array}{c}3 \\
(42.9 \%)\end{array}$ & $\begin{array}{c}2 \\
(22.2 \%)\end{array}$ & $1(9.1 \%)$ & \\
\hline \multirow{3}{*}{$\begin{array}{l}\text { Cuspid } \\
\text { relation } \\
\text { Right }\end{array}$} & Class I & $\begin{array}{c}15 \\
83.3 \% \\
\end{array}$ & $\begin{array}{c}14 \\
(77.8 \%) \\
\end{array}$ & $\begin{array}{c}15 \\
(71.4 \%) \\
\end{array}$ & $\begin{array}{c}14 \\
(58.3 \%) \\
\end{array}$ & \multirow{3}{*}{.084} \\
\hline & Class II & $211.1 \%$ & $\begin{array}{c}4 \\
(22.2 \%)\end{array}$ & $\begin{array}{c}5(23.8 \% \\
)\end{array}$ & 8 (33.3\%) & \\
\hline & Class III & $15.6 \%$ & $0(.0 \%)$ & $1(4.8 \%)$ & $2(8.3 \%)$ & \\
\hline \multirow{3}{*}{$\begin{array}{l}\text { Cuspid } \\
\text { relation } \\
\text { Left }\end{array}$} & Class I & $\begin{array}{c}15 \\
83.3 \% \\
\end{array}$ & $\begin{array}{c}14 \\
(77.8 \%) \\
\end{array}$ & $\begin{array}{c}14 \\
(66.7 \%) \\
\end{array}$ & $\begin{array}{c}15 \\
(62.5 \%) \\
\end{array}$ & \multirow{3}{*}{.120} \\
\hline & Class II & 2 11.1\% & $\begin{array}{c}4 \\
(22.2 \%) \\
\end{array}$ & $\begin{array}{c}6 \\
(28.6 \%)\end{array}$ & $7(29.2 \%)$ & \\
\hline & Class III & $15.6 \%$ & $0(.0 \%)$ & $\begin{array}{c}1(4.8 \% \\
)\end{array}$ & 2 (8.3\%) & \\
\hline \multirow{3}{*}{$\begin{array}{l}\text { Terminal } \\
\text { plane } \\
\text { relation } \\
\text { right }\end{array}$} & $\begin{array}{l}\text { Mesial } \\
\text { step }\end{array}$ & \begin{tabular}{|c|}
13 \\
$(92.9 \%)$ \\
\end{tabular} & $\begin{array}{c}11 \\
(91.7 \%) \\
\end{array}$ & $\begin{array}{c}9 \\
(69.2 \%) \\
\end{array}$ & $\begin{array}{c}13 \\
(68.4 \%) \\
\end{array}$ & \multirow{3}{*}{$.034^{*}$} \\
\hline & Flush & $1(7.1 \%)$ & $1(8.3 \%)$ & $\begin{array}{c}4 \\
(30.8 \%)\end{array}$ & $5(26.3 \%)$ & \\
\hline & \begin{tabular}{|l|} 
Distal step \\
\end{tabular} & $0(.0 \%)$ & $0(.0 \%)$ & $0(.0 \%)$ & $1(5.3 \%)$ & \\
\hline \multirow{3}{*}{$\begin{array}{l}\text { Terminal } \\
\text { plane } \\
\text { relation } \\
\text { left }\end{array}$} & $\begin{array}{l}\text { Mesial } \\
\text { step }\end{array}$ & $\begin{array}{c}13 \\
(92.9 \%)\end{array}$ & $\begin{array}{c}11 \\
(91.7 \%)\end{array}$ & $\begin{array}{c}9(69.2 \% \\
)\end{array}$ & $\begin{array}{c}13 \\
(68.4 \%)\end{array}$ & \multirow{3}{*}{$.034 *$} \\
\hline & Flush & $1(7.1 \%)$ & $1(8.3 \%)$ & $\begin{array}{c}4 \\
(30.8 \%)\end{array}$ & $5(26.3 \%)$ & \\
\hline & Distal step & $0(.0 \%)$ & $0(.0 \%)$ & $0(.0 \%)$ & $1(5.3 \%)$ & \\
\hline Open bite & & $1(5.9 \%)$ & $\begin{array}{c}2 \\
(14.3 \%) \\
\end{array}$ & $\begin{array}{c}9 \\
(52.9 \%) \\
\end{array}$ & $\begin{array}{c}11 \\
(42.3 \%) \\
\end{array}$ & $.003 *$ \\
\hline
\end{tabular}

\section{DISCUSSION}

Children with cerebral Palsy face many physical challenges throughout their lifetimes in addition to social barriers that can have an impact on their quality of life. The neuromuscular problems inherited in CP can affect oral health significantly in several ways. It is generally accepted that oral disease represents a major healthcare problem among people with $\mathrm{CP}$, although there is contradictory information in the literature regarding the prevalence of malocclusion in these patients.

The present cross sectional analytical study was carried out on a group of cerebral palsy children and compared to a group of healthy children that were matched in age and sex. The age range (3-13) was relatively wide to allow the study of different oral manifestations at different developmental stages.

In the present study, the presence of class II cuspid relationship was higher among cerebral palsy children than healthy children. However, the posterior occlusal relations in children with cerebral palsy were similar to that in healthy children with no significant difference. A number of studies concluded that high proportion of CP individuals had Class II malocclusion more than healthy children $(7,21,12,22)$. They suggested that the head and tongue posture, as well as a poor tonus of the orbicularis oris muscle, may be associated with the high prevalence of 
malocclusion in patients with CP. The main risk factors associated with the severity of malocclusion in cerebral palsy patients were mouth breathing, lip incompetence, and long face (11).

In the present study, the mean number of overbite and overjet for cerebral palsy children were significantly higher than that of healthy children. The manifestation of malocclusion in this population may be attributed to abnormal tone of the oro-facial muscles and uncoordinated movement of the lips and tongue. These findings were similar to findings of Franklin et al (10) who observed an increased overbite in children with CP. Cerebral palsy children tended to develop increased overbite due to mouth breathing and tongue thrusting, poor swallowing reflex (23). On the other hand, Magnusson, 1964 (24) and Rosenbaum et al., 1966 (13) found a reduced overbite in children with CP.

In the current study, open bite was observed more in cerebral palsy children (31.1\%) than healthy children (14.8\%). The presence of anterior open-bite and increased over-jet were found more common among children with CP, as has previously been reported $(7,11,25,26)$. This could possibly be related to aberrant tongue movement or positioning, a poor swallow reflex and frequent mouth breathing.

In the current study, the majority of the children exhibited spastic CP (83.9\%) while (65.1\%) of CP children exhibited quadriplegia. These results are in agreement with the previous findings in which high prevalence of $\mathrm{CP}$ children exhibited spastic motor impairment $(27,28)$. In the current study, convex facial profile and decreased overbite were observed more in spastic than non-spastic children. The possible reason is that spasticity induces neuromuscular involvement and, consequently, bone involvement (23) changing facial growth and occlusal development patterns (29).

The GMFCS (Wood \& Rosenbaum 2000) was used, because it provides an objective classification of the motor disability patterns in cerebral palsy children (18). In this study, $57.5 \%$ of the children with $\mathrm{CP}$ had moderate-tosevere self-mobility limitations (GMFCS levels IV and V), requiring greater involvement of the caregivers in all daily activities including daily oral hygiene (30). This was in agreement with Santos et al (31) who noted a high percentage of subjects with CP $(67.6 \%)$ had moderate-tosevere self-mobility limitations (GMFCS levels IV and V). In addition, facial profile, terminal plane relationship as well as open bite were affected by the "GMFCS".

Children with level V had convex facial profile, flush terminal plane, distal step and open bite more than children with level I. A possible explanation for this may be that increase the severity of the neuromuscular deficit result in increase the risk of oral problems (32). Moreover, increasing the severity of $\mathrm{CP}$ children will affect the tone and function of the orofacial muscles so that the facial growth and occlusion might be outside the normal limits.

These results highlighted the importance of including a dentist in the multidisciplinary care team for patients who have $\mathrm{CP}$ as severe malocclusion can trigger conditions such as temporomandibular joint disorders and problems in ingesting food (33). Therefore, treatment of these patients becomes more challenging and necessary. Early, multidisciplinary treatment can help to minimize the harmful effects of malocclusion and improve the quality of life of these patients.

\section{CONCLUSIONS}

Based on the results of this study, the following was concluded:

1) Cerebral palsy children had more class II cuspid relationship than healthy children.

2) Increased overbite and overjet as well as open bite were observed in cerebral palsy children in comparison to healthy children.

3) Facial profile, terminal plane relationship as well as open bite were affected by the Gross Motor Function Classification System "GMFCS".

4) The severity of the neuromuscular deficit is a risk factor for the development of malocclusion in cerebral palsy children.

\section{CONFLICT OF INTEREST}

The authors declare that they have no conflicts of interest.

\section{REFERENCES}

1. Koman LA, Smith BP, Shilt JS. Cerebral palsy. Lancet. 2004;363:1619-31.

2. Rosenbaum P, Paneth N, Leviton A. A report: the definition and classification of cerebral palsy April 2006. Dev Med Child Neurol. 2007;109:8-14.

3. Hirtz D, Thurman DJ, Gwinn-Hardy K, Mohamed M, Chaudhuri AR, Zalutsky R. How common are the “common” neurologic disorders? Neurology. 2007;68,326-37.

4. Yoshida M, Nakajima I, Uchida A. Effect of nitrous oxide on dental patients with cerebral palsy - using an electromyogram (EMG) from orofacial muscles as an index. J Oral Rehabil. 2003;30:324-33.

5. Yoshida M, Nakajima UYT, Nonaka T. Characteristics of lower-jaw-position sensation with respect to oral-jaw functions in patients with cerebral palsy. Pediatric Dent J. 2004;14:23-8.

6. Beckung E, Hagberg G. Neuroimpairments activity limitations, and participation restriction in children with cerebral palsy. Dev Med Child Neurol. 2002;44:309-16.

7. Dos Santos MTBR, Masiero D, Novo NF, Simionato MR. Oral conditions in children with cerebral palsy. J Dent Child. 2003;70:40-6.

8. Saadia AM. Development of occlusion and oral function in children. J Pedod. 1981;5:154-72.

9. Mathur NN, Vaughan TL. Drooling: eMedicine. 2008. Available at: www. emedicine.com/ent/topic629.htm.

10. Franklin DC, Luther F, Curzon ME. The prevalence of malocclusion in children with cerebral palsy. Eur J Orthod. 1996;18:637-43.

11. Miamoto CB, Ramos-Jorge ML, Pereira LJ, Paiva SM, Pordeus IA, Marques LS. Severity of malocclusion in patients with cerebral palsy: determinant factors. Am J Orthod Dentofacial Orthop. 2010;138:394.e1-5.

12. Chandna P, Adlakha VK, Joshi JL. Oral status of a group of cerebral palsy children. J Dent Oral Hyg. 2011;3:1821.

13. Rosenbaum CH, McDonald RE, Levitt EE. Occlusion of cerebral-palsied children. J Dent Res. 1966;45:1696700 . 
14. Miller JB, Taylor PP. A survey of the oral health of a group of orthopedically handicapped children. ASDC J Dent Child. 1970;37:331-2.

15. Sinha N, Singh B, Chhabra KG, Patil S. Comparison of oral health status between children with cerebral palsy and normal children in India: a case-control study. J Indian Soc Periodontol. 2015;19:78-82.

16. El Khatib AA, El Tekeya MM, El Tantawi MA, Omar T. Oral health status and behaviours of children with autism spectrum disorder: a case-control study. Int J Paediatr Dent. 2014;24:314-23.

17.Sankar C, Mundkur N. Cerebral palsy-definition, classification, etiology and early diagnosis. Indian J Pediatr. 2005;72:865-8.

18. Wood E, Rosenbaum P. The gross motor function classification system for cerebral palsy: A study of reliability and stability over time. Dev Med Child Neurol 2000;42:292-6.

19. Robert E. Moyers. Handbook of orthodontics. 4th ed. USA: Year Book Medical Publishers, Inc.; 1998.

20.Pinkham JR, Casamassimo PS, Mc Tigue GJ. Pediatric dentistry: infancy through adolescence. 4th ed. St. Louis: Elservier-Year Book Inc.; 2005.

21. Winter K, Baccaglini L, Tomar S. A review of malocclusion among individuals with mental and physical disabilities. Spec Care Dentist. 2008;28:19-26.

22. Carvalho RB, Mendes RF, Prado Jr RR, Moita Neto JM. Oral health and oral motor function in children with cerebral palsy. Spec Care Dentist. 2011;31:58-62.

23. Strodel BJ. The effects of spastic cerebral palsy on occlusion. J Dent Child. 1987;54:255-60.

24. Magnusson B. Oral conditions in a group of children with cerebral palsy. II. Orthodontic aspects. Odontologisk Revy. 1964;15:41-53.

25. Oredugba FA. Comparative oral health of children and adolescents with cerebral palsy and controls. J Disabil Oral Health. 2011;12:81-7.

26. Du RY, Mcgrath C, Yiu CK, King NM. Oral health in preschool children with cerebral palsy: A case-control community-based study. Int $\mathrm{J}$ Paediatr Dent. 2010;20:330-5.

27. Guerreiro PO, Garcias Gde L. Oral health conditions diagnostic in cerebral palsy individuals of Pelotas, Rio Grande do Sul State, Brazil. Cien Saude Colet 2009: 14: 1939-1946.

28. Lemos ACO, Katz CRT. Oral health conditions and access to dental treatment in patients with cerebral palsy treated at the reference center in Northeastern Brazil. Revista CEFAC. 2012; 14: 861-871.

29. Kirk J, Duyn MASVan. The relationship between oralmotor involvement and growth: A pilot study in a pediatric population with cerebral palsy. J Am Diet Assoc. 1984;84:555-9.

30. Wong V, Chung B, Hui S, Fong A, Lau C, Law B, et al. Cerebral palsy: correlation of risk factors and functional performance using the Functional Independence Measure for Children (WeeFIM). J Child Neurol. 2004;19:887-93.

31. Santos MT, Biancardi M, Guare RO, Jardim JR. Caries prevalence in patients with cerebral palsy and the burden of caring for them. Spec Care Dentist. 2010;30:206-10.
32. Santos MT, Nogueira ML. Infantile reflexes and their effects on dental caries and oral hygiene in cerebral palsy individuals. J Oral Rehabil. 2005;32:880-5.

34.Schwartz S, Gisel EG, Clarke D, Haberfellner $H$. Association of occlusion with eating efficiency in children with cerebral palsy and moderate eating impairment. J Dent Child. 2003;70:33-9. 